\title{
Incidence of Residual Neuromuscular Blocking in Oncological Patients in the Anesthetic Rescue Room: Importance of Objective Monitoring in the Foundation Center of Control of Oncology of the State of Am-
}

\section{azonas - Fcecon}

\section{Fernanda Rondon Pirangy Barros ${ }^{1 *}$, Mirlane Guimarães de Melo Cardoso ${ }^{2}$, Ivandete Coelho Pereira Pimentel ${ }^{2}$, e Mewryane Câmara Brandão Ramos ${ }^{1}$ and Jamilly Rebouças Demosthenes Marques ${ }^{1}$}

${ }^{1}$ Anesthesiology, Resident, Hospital FCECON, Amazonas, Brazil

${ }^{2}$ Anesthesiologist, Hospital FCECON, Amazonas, Brazil

*Corresponding author: Fernanda Rondon Pirangy Barros, Anesthesiology, Resident, Hospital FCECON, Amazonas, Brazil

\begin{abstract}
The present research project aims to evaluate the incidence of residual neuromuscular block in the post-anesthetic recovery room in patients who underwent general anesthesia with mechanical ventilation. It is known that neuromuscular blockers are drugs that interrupt the transmission of nerve impulses at the neuromuscular junction causing muscle paralysis. In addition, they facilitate endotracheal intubation during anesthetic induction and allow for adequate surgical management.

There are several adverse effects resulting from their use, among them: The occurrence of vagolytic and sympatholytic activities that cause cardiovascular alterations or autonomic stimulation. Monitoring the levels of these blockers is of paramount importance because it allows the titration of the drug. By relaxing and paralyzing the muscles, postoperative weakness due to the absence or incomplete performance of the antagonists of this drug is frequent. This situation is known as postoperative residual neuromuscular block.

When it comes to the anesthetic practice to evaluate such situation, the patient's clinic is often the only alternative. The safe use of neuromuscular blockers requires monitoring to qualify muscle relaxation by being measured from a known monitor of four stimuli or Train of Four (TOF).

The residual neuromuscular blocker influences possible clinical complications that may lead to increased morbidity and mortality in the postoperative period. Thus, this project
\end{abstract}

aims to identify the incidence of residual neuromuscular block in the postanesthetic recovery room in order to reduce the cardiorespiratory complications resulting from the use of the adenos polarizing neuromuscular blockers.

\section{Keywords}

Neuromuscular blockers, General anesthesia, Postanesthesia recovery, Residual neuromuscular block, Monitoring

\section{Introduction}

Neuromuscular blockers (NMBs) are drugs used in anesthesiology by stopping the transmission of nerve impulses at the neuromuscular junction. They act to produce relaxation of the muscles, facilitating tracheal intubation and providing good surgical conditions. In addition, they can be used during cardiopulmonary resuscitation and in intensive care units in mechanical ventilation $[1,2]$.

With a similar acetylcholine structure, NMBs have at least one positively charged nitrogen atom and quaternary ammoniums, which allows their action on post-junctional nicotinic receptors of the neuromuscular junction. It is known that neuromuscular transmission begins with the arrival of the impulse in the motor nerve terminal due to the influx of calcium and release

Citation: Barros FRP, Cardoso MGM, Pimentel IPC, e Mewryane CBR, Marques JRD (2019) Incidence of Residual Neuromuscular Blocking in Oncological Patients in the Anesthetic Rescue Room: Importance of Objective Monitoring in the Foundation Center of Control of Oncology of the State of Amazonas Fcecon. Int J Anesthetic Anesthesiol 6:096. doi.org/10.23937/2377-4630/1410096

Accepted: September 21, 2019: Published: September 23, 2019

Copyright: (C) 2019 Pirangy FRF, et al. This is an open-access article distributed under the terms of the Creative Commons Attribution License, which permits unrestricted use, distribution, and reproduction in any medium, provided the original author and source are credited. 
of acetylcholine [3]. Such a situation alters the permeability of the membrane to ions such as potassium and sodium, which diminishes the action potential propagated by the muscular fibers, occurring the muscular contraction. According to the mechanism and duration of action, they are classified as agonist ("depolarizing" BNMs) and nicotinic receptor antagonists ("NMDs"), being these subclassed into long-acting, intermediate and short-acting drugs $[1,2,4]$.

Neuromuscular blockers (NMBs) are drugs in anesthesiology by stopping the transmission of nerve impulses at the neuromuscular junction. They act to produce relaxation of the muscles, facilitating tracheal intubation and providing good surgical conditions. In addition, they can be used during cardiopulmonary resuscitation and in intensive care units in mechanical ventilation $[1,2]$.

The effects produced by NMBs are: Autonomic stimulation, ganglionic blockade, release of histamine, vagolytic and sympatholytic activities which leads to cardiovascular changes. The BNM potency is measured from the dose-response relationship. The effective dose of NBM is understood to be the dose that decreases the muscle strength of the anesthetized patient by $95 \%$ in response to a simple stimulus. The value is obtained through the stimulation of the ulnar nerve followed by the recording of the mechanical response of the adductor muscle of the thumb [5]. The literature generally indicates that adequate tracheal intubation requires at least two effective doses of any of the BNMs. The intubation conditions clinically acceptable by direct laryngoscopy are: Relaxed jaw, open and immobile vocal cords and absence of diaphragmatic movements [1,2].

Reversal of neuromuscular blockade can be achieved through the use of anticholinesterase agents or reversal agents specific for rocuronium and vecuronium. Adequate intraoperative use with monitoring of neuromuscular transmission allows the titration of the drug and confirms recovery of NMB prior to tracheal extubation [3]. In the absence of such monitoring, the blockade should be routinely antagonized due to the unpredictability of its spontaneous recovery. However, the medications used for this purpose are not exempt from side effects, among them, the risk of oxygen desaturation at the beginning of the postoperative period is mentioned, which occurs due to the attempt to antagonize the deep block once that anticholinesterases are unable to reverse this level of BNM [1,6].

The diagnosis of different degrees of relaxation at the end of anesthesia can be made with clinical evaluation of the patient. Factors such as: Ability to lift and hold the head, raise the legs, shake hands for five seconds, open the eyes, detection of tidal volume with vital capacity above $15 \mathrm{ml} . \mathrm{kg}$ and negative inspiratory force of 20 to $25 \mathrm{~cm} \mathrm{H}_{2} \mathrm{O}$ are the minimum acceptable in the recovery of neuromuscular transmission. However, these parameters are not very effective because for their evaluation it is necessary a comparison of the current values of the patient with those presented in the preoperative period [7]. In addition, these agents are influenced by other drugs used in surgery. In doubtful situations it is fundamental that the registry is used through objective methods.

The best way to evaluate the integrity of the neuromuscular transmission is by checking the electrical stimulation in a peripheral motor nerve, in order to verify or not the contraction of the muscle innervated. Residual curare blocks can only be confirmed using quantitative or qualitative monitoring of neuromuscular transmission [7]. Thus, an action potential in the peripheral motor nerve is easily accessible by the application of an electric stimulus. Quantitative and objective methods are the most recommended, being the accelerometer, typing and electromyography preferable. The stimulation pattern used in the design is the four-train-of-four (TOF) sequence and accelerometry with thumb adductor monitoring and ulnar nerve stimulation [5].

The sequence of four stimuli consists in the emission of this number of stimuli at a frequency of $2 \mathrm{~Hz}$, that is, four stimuli in two seconds. An interval of $10 \mathrm{sec}-$ onds should be expected between successive TOFs in order to avoid muscular fatigue during measurements. This response means that there is a rapid depletion of available acetylcholine stores, but it becomes slow to the point that it does not lead to muscular mobilization [6].

Blocking can be assessed by the number of muscular responses and by the relationship between the amplitude of the fourth and the first response of the sequence (T4/T1 ratio). In the blockade, a decrease in the amplitude of response proportional to the relaxation depth is observed. In their absence all four responses should be of equal amplitude [7]. The loss of the fourth response corresponds to $75-80 \%$ of the first stimulus block. The disappearance of the third, second and first contractions corresponds to the blockade of about $85 \%$, $90 \%$ and $98-100 \%$, respectively $[1,3]$.

The value of T4/T1 > 0.7 suggests recovery of the diaphragm block. However, it is not sufficient to prevent aspiration of gastric contents. Value of T4/T1 > 0.8 represents the capacity of the patient to generate $90 \%$ of their tidal volume [6]. Values of the T4/T1 ratio below 0.9 evaluate worsening of the ventilatory response to hypoxia and the function of the pharyngeal and upper esophageal sphincter muscles, predisposing to pulmonary aspiration and ventilatory complications. In incomplete depolarizing blockade, because no fatigue occurs, the four responses are practically identical, which maintains the T4/T1 ratio between 0.9 and 1.0 [1,3].

The residual effect of neuromuscular blockers is reversed with neostigmine, which inhibits the action of the enzyme acetylcholinesterase in the neuromuscular 
junction, leading to the reduction of the acetylcholine degradation, potentializing its action. Such a method should be performed at the end of surgery and not before some degree of spontaneous blockade resolution has occurred [6]. Early administration of anticholinesterases may be ineffective due to the high rate of receptor uptake by NMBs. Concurrent use of antimuscarinic agents such as atropine or glycopyrrolate is necessary because of the following effects: Bradycardia, miosis, increased peristalsis, nausea, bronchospasm, increase of bony secretions, sweating and salivation to minimize its side effects $[3,8]$.

Therefore, it is fundamental that there is complete recovery of the neuromuscular block for the resumption of control of the pharyngeal function and the action of the respiratory muscles. Otherwise, there is an increased risk of aspiration, inadequate recovery of lung function and ventilatory response to impaired hypoxia. The aim of this study was to evaluate the incidence of residual neuromuscular block in the post-anesthetic recovery room between patients receiving intermediate-acting neuromuscular blockers during general anesthesia with mechanical ventilation [9].

The diagnosis of deep relaxation degrees at the end of anesthesia can be done with the use of clinical tests performed in the bed, however, residual curare blocks are only detected using objective monitoring of the neuromuscular transmission, through the sequence of four stimuli (TOF) and accelerometry. Although there is a consensus in the literature about the diagnosis, as well as the consequences of this complication, the frequency of neuromuscular transmission monitors is still very low, even in developed countries [7].

Thus, the present study aims to evaluate the incidence of residual neuromuscular block in the post-anesthetic recovery room among patients who received intermediate-acting neuromuscular blockers during general anesthesia with mechanical ventilation.

\section{Justification}

The safe use of neuromuscular blockers requires monitoring. Currently, measurement of neuromuscular function in response to electrical stimulation of a motor nerve is the most effective method, although ineffective clinical criteria in the detection of residual block are still used. With the incidence of postoperative morbidity from $9 \%$ to $47 \%$ after residual neuromuscular blockade leading to an increase in complications in the immediate postoperative period, such as a decrease in upper esophageal sphincter tone with increased risk of gastric juice passive regurgitation with consequent pneumonia aspiration was around 7 to $29 \%$.

In clinical practice, pharmacological reversal of muscle relaxants is effected with an anticholinesterase preceded or associated with anticholinergic. More re- cently, modified cyclodextrin, sugammadex, has been introduced, which is able to encapsulate rocuronium. Due to the competitive occupation of the binding sites not occupied by the neuromuscular blocker, neuromuscular transmission becomes effective. However, electrophysiological studies have shown that the use of anticholinesterases does not lead to the elimination of the neuromuscular blocker from its binding site. Thus, it is possible that after the end of the anticholinesterase effect, the patient has residual neuromuscular block.

Due to the high risk of serious postoperative complications, the FCECON was chosen to carry out the project. It is well known that most surgeries of the oncology category are large and, therefore, require general anesthesia with mechanical ventilation. The monitoring of neuromuscular blockade, train of four is performed during the intraoperative period by anesthesiologists because of the restricted amount of equipment, so clinical evaluation is used for the recovery of the neuromuscular blockade. Therefore, the development of this will contribute to evaluate the incidence of residual neuromuscular block in order to prevent postoperative complications using gold standard monitoring.

Information on comorbidities and clinical characteristics will be researched, relevant to the current purpose of the project. In addition, the risks of complications arise due to the patient's own clinical condition and antitumor treatment.

Thus, the project aims to evaluate the degree of residual paralysis in the postanesthetic recovery room, which directly implies the improvement of late recurrence and the use of NMB monitoring in anesthetic procedures in order to avoid deleterious outcomes to the patient.

\section{Methodology}

This is a prospective and observational study, approved by the Research Ethics Committee (CEP) of the Center for Oncology Control Foundation (FCECON), under the opinion of $n$ o 2497477, on $02 / 16 / 2018$, according to the norms ethics of resolution 466/2012 in force in Brazil. The Informed Consent Form (TCLE) was obtained in writing from all participants of the research.

The target population consisted of patients submitted to general anesthesia with mechanical ventilation in oncologic surgery from August 2017 to July 2018, at FCECON. The sample was calculated based on the target population of 800 patients, estimated proportion of $20 \%$, sample error of $5 \%$ and confidence of $95 \%$, totaling 190 patients.

Patients were recruited through the sample for convenience. The inclusion criteria were: (1) Informed consent form signed by the patient; (2) Patients submitted to oncologic surgeries who used the neuromuscular blocker in orotracheal intubation and maintenance of 
general anesthesia in mechanical ventilation. Exclusion criteria were: (1) Patients admitted to the anesthetic recovery room intubated, hypothermic or who received succinylcholine only as a neuromuscular blocker; (2) Patients who perform anesthetic techniques such as neuroaxis blocks, peripheral and total venous blocks without administration of muscle relaxants; (3) Patients who refused to be part of the study.

Eligible patients referred to the post-anesthetic recovery unit (PACU) were assessed clinically and by objective monitoring, through the four-stimulus sequence (SQE), at the initial time of anesthetic recovery, i.e., during the immediate postoperative period.

Patients were monitored at the time of his arrival in the PACU with cardioscope, digital oximeter and mean blood pressure non-invasively, temperature and peripheral nerve stimulator, in addition to receiving oxygen. For the monitoring of neuromuscular function, the four-stimulus sequence (TOF-watch SX acceleromyography) was used. The preparation for scoring was performed with alcohol cleansing the skin, and then placed two electrodes in the medial region of the wrist, ulnar nerve topography, followed by monitoring the neuromuscular function of the adductor muscle of the thumb using the TOF-Watch SX acceleromyography. Patients with residual neuromuscular block were those with T4/ T1 $<0.9$, ie, TOF $<90 \%$.

After the SQE measurement in the PACU, when we checked for residual block, all patients with $\mathrm{T} 4 / \mathrm{T} 1$ between 0.7 and 0.3 received $20 \mu \mathrm{g} . \mathrm{kg}^{-1}$ of neostigmine and $10 \mu \mathrm{g} . \mathrm{kg}^{-1}$ of atropine. Those with $\mathrm{T} 4 / \mathrm{T} 1$ ratio $<0.3$ received $40 \mu \mathrm{g} . \mathrm{kg}^{-1}$ of neostigmine and $20 \mu \mathrm{g} \cdot \mathrm{kg}^{-1}$ of atropine. Patients who had less than two responses to SQE were reintubated.

Data from the sample were analyzed and described, such as: age, sex, type of anesthesia, time of surgery, time between the last administration of neuromuscular blocker and SQE measurement in PACU, total dose of neuromuscular blocker and drugs that interfere with neuromuscular blockade. The data were organized into frequency tables with the aid of the Office Excel program. The software used for data analysis was the Epi Info program, version 7.2.

\section{Results and Discussion}

In total, 190 patients were evaluated, corresponding to the total number of samples proposed, of these 147 females and 43 males, with a mean age of 52.4 years, Table 1.

The mean surgical time was two and a half hours (02h: $30 \mathrm{~min})$, ranging from seven $(07 \mathrm{~h}: 00 \mathrm{~min})$ to one (01h: $00 \mathrm{~min}$ ) of surgery. The main anesthetic technique applied was Balanced General Anesthesia, followed respectively by combined general anesthesia, general anesthesia with epidural block, general anesthesia with subarachnoid block, general venous anesthesia and general anesthesia associated with spinal anesthesia, Table 2.

The maximum time between leaving the operating room, with arrival in the PACU, and monitoring with TOFwatch was 5 minutes. Of the 190 patients evaluated, residual blockade was identified in $35 \%$; among these, in $31 \%$, the pharmacological reversal of the neuromuscular blockade was not performed. The overall mean value of SQE was T4/T1 $=0.89$, that is, TOF equivalent to $89 \%$, Table 3 and Table 4 . In the sample analyzed, eight (8) patients required a thermal blanket to control hypothermia, in addition, in however, the statistical analysis did not show a positive correlation between these postoperative complications and the residual neuromuscular blockade of the patients in this sample, and it can be attributed to other surgical variables [10].

The use of muscle relaxants has brought several advantages in the field of anesthesiology, in the op-

Table 1: Distribution of gender and age in the sample.

\begin{tabular}{|l|l|l|}
\hline Gender & $\begin{array}{l}\text { Absolute } \\
\text { frequency }\end{array}$ & $\begin{array}{l}\text { Relative } \\
\text { frequency (\%) }\end{array}$ \\
\hline Female & 147 & $77 \%$ \\
\hline Men & 43 & $23 \%$ \\
\hline Total & 190 & $100 \%$ \\
\hline $\begin{array}{l}\text { Average Age } \\
\text { Range (years) }\end{array}$ & Média (anos) & \\
\hline & 52.4 & \\
\hline
\end{tabular}

Table 2: Types of general anesthesia used.

\begin{tabular}{|l|l|l|}
\hline Type of Anesthesia & $\begin{array}{l}\text { Absolute } \\
\text { frequency }\end{array}$ & $\begin{array}{l}\text { Relative } \\
\text { frequency (\%) }\end{array}$ \\
\hline $\begin{array}{l}\text { Combined General } \\
\text { Anesthesia }\end{array}$ & 41 & $21.5 \%$ \\
\hline $\begin{array}{l}\text { General Venous } \\
\text { Anesthesia }\end{array}$ & 3 & $1.6 \%$ \\
\hline $\begin{array}{l}\text { General Anesthesia } \\
\text { Balanced }\end{array}$ & 146 & $77 \%$ \\
\hline Total & 190 & $100 \%$ \\
\hline
\end{tabular}

Table 3: Result of the monitoring by the sequence of four stimuli.

\begin{tabular}{|l|l|}
\hline SQE (TOF) & Value (\%) \\
\hline Overall average & $89 \%$ \\
\hline Mean of the residual blockade & $68 \%$ \\
\hline Mean of residual blockage without reversal & $72 \%$ \\
\hline
\end{tabular}

Table 4: Evaluation of residual block by level.

\begin{tabular}{|l|l|l|}
\hline $\begin{array}{l}\text { Residual Block Level } \\
\text { (T4/T1) }\end{array}$ & $\begin{array}{l}\text { Absolute } \\
\text { Frequency }\end{array}$ & $\begin{array}{l}\text { Relative } \\
\text { Frequency (\%) }\end{array}$ \\
\hline Up to 0.4 & 2 & $3 \%$ \\
\hline$>0.4$ to 0.7 & 25 & $37 \%$ \\
\hline$>0.7$ to 0.8 & 34 & $51 \%$ \\
\hline$>0.8$ to 0.9 & 6 & $9 \%$ \\
\hline
\end{tabular}


timization of surgical conditions. However, there are several risks in the use of neuromuscular blocking agents, the most critical being inadequate recovery of neuromuscular function, leading to complications due to upper airway muscle weakness [11]. Accordingly, reversible agents such as acetylcholinesterase inhibitors and Sugamadex are used to antagonize non-depolarizing muscle relaxant effects and prevent complications due to residual curarization, as observed in this research.

Recently, neuromuscular transmission monitoring devices have become available. However, according to the study by Baillard, et al. [12], despite a gradual improvement, $40 \%$ of patients are not monitored objectively when administered NMB during surgery. Neuromuscular transmission monitoring devices allow precise titration, more rational use of NMB agents, and therefore a reduction in the incidence of postoperative residual neuromuscular blockade [12].

Previous studies have shown that residual neuromuscular block is related to the absence of reversing agents. In this study, the results corroborate the previous ones, since it was observed that the neuromuscular function in the PACU was more frequently adequate in patients who received anticholinesterase drugs.

The data presented in this study are in agreement with previous studies that demonstrated that approximately $40 \%$ of the patients who receive intermediate-acting NMB have TOF with ratios below $0.9[13,14]$.

\section{Conclusion}

Incidence of residual neuromuscular blockade was observed in $35 \%$ of patients in the post-anesthetic recovery room among patients who received intermediate-acting neuromuscular blockers during general anesthesia. However, there was no positive correlation between the incidence of residual blockade and the variables dose and time of administration of BNM, or even physical characteristics of the patients.

\section{References}

1. Mathias LAST, Bernardis RCG (2012) Paralisia Residual
Pós-Operatória. Revista Brasileira de Anestesiologia 62: 439-450.

2. Luciano Carlos Gomes de Miranda, Louis Barrucand, José Costa TSA, Núbia Verçosa (2008) Estudo Comparativo entre Uma e Duas Doses Efetivas (DE95) de Rocurônio para a Intubação Traqueal. Revista Brasileira de Anestesiologia 58: 202-209.

3. Almeida MCS (2004) O Uso de Bloqueadores Neuromusculares no Brasil. Rev Bras Anestesiol 54: 850-864.

4. Miller RD, Pardo MC (2012) Bases da Anestesia. (6 $6^{\text {th }}$ edn), Elsevier, Rio de Janeiro, 775.

5. Barash PG (2017) Fundamentos de Anestesiologia Clínica. Porto Alegre Artmed.

6. Souza CM, Romero FE, Tardelli MA (2011) Avaliação do Bloqueio Neuromuscular em Crianças no Momento da Reversão do Bloqueio e da Retirada da Cânula Endotraqueal. Revista Brasileira de Anestesiologia 61: 145-155.

7. Marcos Vinícius Pimentel Cardoso, Maíla Aparecida Vinhal Andrade, Joana Angélica Vaz de Melo, William Costa Rocha, Flávia Aparecida Resende, et al. (2016) Bases da Monitorização Neuromuscular. Revista Médica de Minas Gerais 26: S34-S38.

8. Giovani de Figueiredo Locks, Ismar Lima Cavalcanti, Nadia Maria Conceic ão Duarte, Rafael Martins da Cunha e Maria Cristina Simões de Almeida (2015) Use of neuromuscular blockers in Brazil. Rev Bras Anestesiol 65: 319-325.

9. Daniel Gamermann, Carmen Moret-Tatay, Esperanza Navarro-Pardo, Pedro Fernández De Córdoba Castellá (2017) The Small-World of 'Le Petit Prince': Revisiting the Word Frequency Distribution. 32: 301-311.

10. Miller RD, Eriksson LI, Fleisher LA, Wiener-Kronish JP, Cohen NH (2015) Miller's anesthesia. ( $8^{\text {th }}$ edn), Elsevier Health Sciences, Oxford, UK, 3312.

11. Green MS, Venkatesh AG, Venkataramani R (2017) Management of residual neuromuscular blockade recovery: Age-old problem with a new solution. Case Reports in Anesthesiology.

12. Baillard C, Clec'h C, Catineau J, Salhi F, Gehan G, et al. (2005) Postoperative residual neuromuscular block: A survey of management. $\mathrm{Br} \mathrm{J}$ Anaesth 95: 622-626.

13. Murphy GS, Szokol JW, Avram MJ, Greenberg SB, Shear TD, et al. (2015) Residual neuromuscular block in the elderly: Incidence and clinical implications. Anesthesiology 123: 1322-1336.

14. Brull SJ, Naguib M, Miller RD (2008) Residual neuromuscular block: rediscovering the obvious. Anesth Analg 107: 11-14. 